\title{
Lesser spot-nosed monkeys coordinate alarm call production with associated Campbell's monkeys
}

\author{
Auriane Le Floch ${ }^{1} \cdot$ Alice Bouchard ${ }^{1} \cdot$ Quentin Gallot ${ }^{1} \cdot$ Klaus Zuberbühler $^{1,2}$
}

Received: 17 February 2021 / Revised: 7 July 2021 / Accepted: 9 July 2021 / Published online: 26 July 2021

(c) The Author(s) 2021

\begin{abstract}
Forest monkeys often form semi-permanent mixed-species associations to increase group-size related anti-predator benefits without corresponding increases in resource competition. In this study, we analysed the alarm call system of lesser spotnosed monkeys, a primate that spends most of its time in mixed-species groups while occupying the lowest and presumably most dangerous part of the forest canopy. In contrast to other primate species, we found no evidence for predator-specific alarm calls. Instead, males gave one general alarm call type ('kroo') to three main dangers (i.e., crowned eagles, leopards and falling trees) and a second call type ('tcha-kow') as a coordinated response to calls produced in non-predatory contexts ('boom') by associated male Campbell's monkeys. Production of 'kroo' calls was also strongly affected by the alarm calling behaviour of male Campbell's monkeys, suggesting that male lesser spot-nosed monkeys adjust their alarm call production to another species' vocal behaviour. We discuss different hypotheses for this unusual phenomenon and propose that high predation pressure can lead to reliance on other species vocal behaviour to minimise predation.
\end{abstract}

\section{Significance statement}

Predation can lead to the evolution of acoustically distinct, predator-specific alarm calls. However, there are occasional reports of species lacking such abilities, despite diverse predation pressure, suggesting that evolutionary mechanisms are more complex. We conducted field experiments to systematically describe the alarm calling behaviour of lesser spot-nosed monkeys, an arboreal primate living in the lower forest strata where pressure from different predators is high. We found evidence for two acoustically distinct calls but, contrary to other primates in the same habitat, no evidence for predator-specific alarms. Instead, callers produced one alarm call type ('kroo') to all predator classes and another call type ('tcha-kow') to non-predatory dangers, but only as a response to a specific vocalisation of Campbell's monkeys ('boom'). The production of both calls was affected by the calling behaviour of Campbell's monkeys, suggesting that lesser spot-nosed monkey vocal behaviour is dependent on the antipredator behaviour of other species. Our study advances the theory of interspecies interactions and evolution of alarm calls.

Keywords Polyspecific association · Predation · Acoustic analyses · Playback experiments · Vocal communication · Cercopithecus petaurista

\section{Introduction}

Communicated by D P. Watts

Auriane Le Floch

aurianelefloch@me.com

1 Institute of Biology, University of Neuchâtel, Neuchâtel, Switzerland

2 School of Psychology and Neuroscience, University of St Andrews, St Andrews, Scotland, UK
A robust finding in animal behaviour research is that many social species produce acoustically distinct alarm calls to different predators. In primates, the phenomenon has first been studied systematically in East African vervet monkeys (Cercopithecus aethiops) with evidence for acoustically distinct alarm calls to martial eagles, leopards and pythons (Struhsaker 1967) and corresponding, adaptive anti-predator responses in listeners (Seyfarth et al. 1980). Similar findings have been reported in a range of other species, such as Diana 
monkeys (Cercopithecus diana, Zuberbühler et al. 1997), Campbell's monkeys (Cercopithecus campbelli, Zuberbühler 2001), putty-nosed monkeys (Cercopithecus nictitans, Arnold and Zuberbühler 2006), sooty mangabeys (Cercocebus atys, Range and Fischer 2004), lemurs (Eulemur fulvus rufus and Propithecus verreauxi, Fichtel and Kappeler 2002), meerkats (Suricata suricatta, Manser 2001) and many bird species (Suzuki 2012; Grieves et al. 2014; Cunningham and Magrath 2017). In some animal species, callers respond to dangers with complex series of alarm calls that encode information at the sequence level (Schel et al. 2010). For example, black-fronted titi monkeys (Callicebus nigrifrons) produce two types of alarm calls in long sequences that refer to both predator type and location (Berthet et al. 2019), a phenomenon also found in non-primate species (meerkats, Rauber 2020; Japanese great tits (Parus major), Suzuki 2014; pied babblers (Turdoides bicolor), Engesser et al. 2016). In some species, predator alarm calls strongly resemble aggressive calls given to conspecifics, suggesting that listeners consider contextual information to infer the cause of an event (titi monkeys, Cäsar et al. 2012; lemurs, Fichtel and Kappeler 2002; Fichtel and van Schaik 2006; saddleback tamarins (Saguinus fuscicollis), Kirchhof and Hammerschmidt 2006; vervet monkeys, Price et al. 2015).

Alarm calls are usually an integral part of a more general anti-predator strategy, such as mobbing behaviour (Baker and Becker 2002; Graw and Manser 2007; Griesser 2009; Templeton 2005), predator deterrence (Caro 1986; Zuberbühler et al. 1999) or cryptic behaviour (Shalter 1978; Klump et al. 1986), and they can also play an important role in mixed-species associations (Magrath et al. 2015). In forest primates, for example, different species can assemble in large mixed-species groups, which increases the number of sentinels in visually difficult habitats beyond the speciesspecific group size limits (Cords 1990; Wolters and Zuberbühler 2003). Presumably, individuals of mixed-species associations know each other individually, not only within but also between species, and there is solid evidence that they understand each other's alarm calls (Zuberbühler 2000, 2002; Rainey et al. 2004; Candiotti et al. 2012; Coye et al. 2015; Magrath et al. 2015).

In primates, mixed-species groups are often semi-permanent (Struhsaker 1981; Mitani 1991; Chapman and Chapman 1996, 2000), which is facilitated by the fact that different species exploit unique niches and thus minimize interspecies competition (Buzzard 2010). In the Taï Forest (Ivory Coast), up to eight monkey species regularly form mixed-species associations (McGraw et al. 2007). Amongst them, Diana monkeys typically forage in the highest canopy parts with a fruit-rich diet, whereas Campbell's monkeys have a more generalist diet and exploit levels below the main canopy while lesser spot-nosed monkeys (Cercopithecus petaurista) prefer foliage in the lower levels with a large proportion of leaves in their diet (McGraw 2000; Wolters and Zuberbühler 2003; Kane and McGraw 2017; McGraw and Daegling 2020). These three guenon species spend the majority of their time in association (75-88\%, Buzzard 2010).

Although all Taï Forest monkeys suffer from predation by chimpanzees (Pan troglodytes), leopards (Panthera par$d u s$ ), crowned eagles (Stephanoaetus coronatus) and humans (Boesch and Boesch 1989; Jenny 2005), foraging close to the ground is probably most dangerous due to high risks of sudden and close predator encounters (Mourthé et al. 2007). Even attacks from aerial predators are common in the lower strata of the canopy, as crowned eagles have been observed waiting for approaching monkeys within the canopy in order to launch themselves onto individuals passing underneath (Shultz 2008).

While polyspecific associations provide well-documented antipredator benefits (see Stensland et al. 2003 for review), they also require compromising in travel and time budget (Heymann 2011) and coordination in anti-predator responses, including alarm calling (Suzuki 2016), a potentially costly behaviour that attracts attention to the caller (Sherman 1977; Goodale et al. 2019). This is especially true for male forest guenons that have evolved loud alarm calls that transmit over long distances in dense vegetation, presumably due to a secondary, sexually selected function of dissuading sexual rivals (Zuberbühler 2004). This leads to the prediction that male forest monkeys should economise their alarm calling efforts whenever possible. Indeed, in Diana monkeys, males wait to produce their alarm calls until the females have started giving predator-specific alarm calls (Stephan and Zuberbühler 2016). Similarly, in Thomas langurs (Presbytis thomasi), males stop giving alarm calls as soon as other group members have responded with their own alarm calls (Wich and de Vries 2006), demonstrating that male alarm calling can be socially coordinated and that callers try to economise call production.

Whether similar social dynamics take place in mixedspecies associations has, to our knowledge, never been systematically investigated. In this study, we focus on lesser spot-nosed monkeys and their most frequent association partners in the Taï Forest, Campbell's monkeys (McGraw et al. 2007). Both species are arboreal and live in groups of one fully adult male and several adult females with their offspring (Rowe 1996). Both are comparably cryptic primates that are difficult to locate because of their inconspicuous coloration as well as their very soft and infrequent contact calls, a likely adaptation to their foraging niche in the lower forest strata (McGraw et al. 2007). Overall, this cryptic lifestyle appears to provide both species with a considerable adaptive advantage, especially in dealing with hunting pressure from chimpanzees and humans (Boesch and Boesch 1989; Boesch 1994; Covey and McGraw 2014). Indeed, both species are less threatened by extinction than the more conspicuous 
Western red colobus (Piliocolobus badius) and Diana monkeys, which suffer from intense levels of human poaching and are IUCN-listed as endangered (Matsuda Goodwin et al. 2017, 2019; Koné et al. 2019; McGraw et al. 2020).

Lesser spot-nosed monkey anti-predator strategies have received little attention in the literature so far. When disturbed by human presence, males produce head-bob displays and a purring alarm call, in response to which females and offspring retreat (McGraw 2000; Rowe 1996). Early reports have suggested that male alarm calls contain subtle, contextspecific acoustic variability (Kambiré 2015; Kouassi 2008), similar to what has been described for Barbary macaque (Macaca Sylvanus) or chamca baboon (Papio cynocephalus ursinus) alarm calls (Fischer et al. 2001, 2010). Meaningful acoustic variations have also been reported in other species' alarm calls, such as Siberian jay (Perisoreus infaustus) alarm calls to different predator behaviours (perched, searching or attacking hawks; Griesser 2008), titi monkey alarm calls to different predator locations (Berthet et al. 2019), black-capped chickadee (Poecile atricapillus) alarm calls to different predator sizes (Templeton 2005) and meerkat, Campbell's monkey and blue monkey (Cercopithecus mitis) alarm calls to different event urgencies and predator types (Lemasson et al. 2010; Townsend et al. 2012; Murphy et al. 2013).

Field observation from McGraw et al. (2007) suggested that lesser spot-nosed monkeys produce a loud call in direct response to Campbell's monkey 'boom', a short and lowpitched call produced by the air-sacs typically in pairs, usually in non-predatory contexts such as falling trees, group movements or neighbouring encounters (Zuberbühler 2002; Ouattara et al. 2009a). However, the function of this behaviour remains unknown. Oates (1985) described a loud call from a male lesser spot-nosed monkey as a "...loud, explosive burst of broad-band energy, followed by a train of quieter, low-pitched (energy concentrated around $0.6 \mathrm{kHz}$ ), closely-spaced 'urr' units" (p. 32). Aside from such anecdotal information, lesser spot-nosed monkey vocal behaviour has not yet been explored systematically, in contrast to the other Taï guenons (Zuberbühler et al. 1997; Eckardt and Zuberbühler 2004; Ouattara et al. 2009b; Schlenker et al. 2016).

We used playback experiments to document male lesser spot-nosed monkey vocal responses when encountering three types of dangers: eagles, leopards and falling trees. Specifically, we investigated whether male vocal responses held acoustic differences (i.e., whether there were contextspecific alarm calls or call variants) and whether there was variation in the effort of production (number of calls, rate, latency) according to the type of danger encountered. We also analysed whether Campbell's monkey alarm calling behaviour influenced the call production effort of lesser spotnosed monkey. Finally, we explored male lesser spot-nosed monkey vocal response to three Campbell's monkey alarm call types typically produced towards eagles, leopards and falling trees.

\section{Method}

\section{Study site}

The study was conducted in the Taï National Park (Ivory Coast), about $25 \mathrm{~km}$ southeast of the town of Taï. Data were collected in an approximately $50 \mathrm{~km}^{2}$ study area surrounding the 'Centre de Recherche en Ecologie' ( $5^{\circ} 50^{\prime} \mathrm{N}, 7^{\circ} 21^{\prime}$ W) field station by KZ (1994-2002) and by ALF during a second field period (July-December 2017).

\section{Data collection and materials}

Data collection consisted of eliciting and recording alarm calls in mixed-species groups of monkeys by simulating natural disturbances with different playback stimuli. We analysed the vocal responses of male lesser spot-nosed monkeys, a species that lives in small groups with stable home ranges of about $0.7 \mathrm{~km}^{2}$ (McGraw et al. 2007). Like other Taï monkeys, lesser spot-nosed monkeys are hunted by crowned eagles, leopards, chimpanzees and humans (McGraw and Zuberbühler 2008). Non-predatory dangers are accidental bites by stationary snakes (Foerster 2008), such as Gaboon vipers (Bitis gabonica) that usually feed on smaller prey (Penner et al. 2008), falling trees or large branches (Vooren 1986) and occasional lightning strikes, which can lead to fatalities in primates and other animals.

We located mixed-species groups, mainly by listening to the conspicuous vocalisations of Diana monkeys. We recorded their location (GPS coordinates with a Garmin GPS map $62 \mathrm{~s}$ or estimated position on a customised grid map; see Online Resource 1, Fig. S1) and monitored their vocal behaviour for up to $30 \mathrm{~min}$ to ensure that no alarm calls were given while approaching to about $25-50 \mathrm{~m}$ (outside visual range). To keep data points independent, we took into account the home range of lesser spot-nosed monkeys (approximately $0.7 \mathrm{~km}^{2}$; McGraw et al. 2007) and the natural occurrence of leopard and crowned eagle encounters, male Campbell's monkey alarm calling and falling tree events (Vooren 1986; Zuberbühler and Jenny 2002; McGraw et al. 2007). Based on these data and considerations, we only considered trials if groups were located at least $950 \mathrm{~m}$ (GPS location) or $1200 \mathrm{~m}$ (grid map) apart and if trials with the same stimulus were separated by at least 30 days.

Vocal responses were elicited by simulating the presence of danger, i.e., by playing back $14 \mathrm{~s}$ of crowned eagle shrieks, $14 \mathrm{~s}$ of leopard growls or $7 \mathrm{~s}$ of the thundering sound of a falling tree. Campbell's monkey playbacks consisted of 
series of 'krak' alarms (produced in the presence of a leopard), 'hok' alarms (produced in the presence of an eagle), or 'boom' calls (produced in non-predatory contexts such as falling trees) (Ouattara et al. 2009a). See Online Resource 1, Table S1 for details on playback stimuli. Campbell's monkey playbacks of 'krak', 'hok' and 'boom' series were used to provoke matching alarm call responses in Diana monkeys (Zuberbühler 2000, 2002), suggesting that their meanings can be transmitted across species. It was not possible to record data blindly because our study involved animals in the field.

ALF played back sounds from an iPhone 3GS connected to an Alpha speaker (AER, The Acoustic People; frequency range $60-18,000 \mathrm{~Hz})$. KZ played back sounds from a Sony WMD6C Professional Walkman connected to a Nagra DSM speaker-amplifier (frequency response $60-15,000 \mathrm{~Hz} \pm 4 \mathrm{~dB}$ ). Vocalisations were tape-recorded with a Sony TCM5000EV cassette recorder and a Sennheiser ME88 or ME67 directional microphone (frequency response, $40-20,000 \mathrm{~Hz} \pm 2.5 \mathrm{~dB}$; KZ) or a Marantz 661 solid-state recorder $(44.1 \mathrm{kHz}$ sampling rate, 16 bits accuracy, WAV format) and a Sennheiser ME67 directional microphone (frequency response, $40-20,000 \mathrm{~Hz} \pm 2.5 \mathrm{~dB}$; ALF). Prior to analysis, all cassette recordings were digitised (44.1 kHz sampling rate, 16 bits accuracy, WAV format) with Audacity 2.1.0 using a TASCAM CD-A500 and a Technics M280 cassette player connected via a $3.5 \mathrm{~mm}$ jack to $2 \times$ RCA phono stereo audio cable to a desktop computer.

\section{Call coding}

We analysed the vocalisations produced during the $2 \mathrm{~min}$ following an eagle, leopard or falling tree playback to explore the overall response pattern of male lesser spotnosed monkeys. Regarding playbacks of Campbell's monkey alarm calls, we investigated the males' immediate responses, i.e., vocalisations produced during the first $30 \mathrm{~s}$ following playbacks. In addition, we recorded any naturally occurring lesser spot-nosed and Campbell's monkeys male alarm calls to support the call classification analyses and for graphical representations (see Online Resource 1, Table S2).

Male lesser spot-nosed and Campbell's monkeys' vocal responses were coded by ALF using the acoustic software Raven Pro 1.5.0 (FFT size 1024, Hann window, hop size $6.96 \mathrm{~ms}$ ). For lesser spot-nosed monkeys, we discriminated three main call types, 'kroo', 'tcha' and 'kow', by visual inspection of spectrograms and by ear. Campbell's monkey vocal responses to playbacks were coded using spectrograms and audio samples from previous studies (Zuberbühler 2001; Ouattara et al. 2009a, b). For each call, ALF coded the call type, start and end time, quality (good/bad, depending on interference and background noise), species identity (lesser spot-nosed or Campbell's monkeys) and trial ID. A second observer (QG) recoded $20 \%$ of the lesser spot-nosed monkey vocal dataset and confirmed the reliability of these classifications (Cohen's Kappa, $k=0.85$; 'irr' R package v0.84.1; Gamer et al. 2019).

Raven Pro 1.5.0 was set to automatically extract acoustic parameters after ALF manually selected calls by inspecting their spectrograms (see Kershenbaum et al. 2016). The following acoustic parameters were extracted for both male lesser spot-nosed and Campbell's monkeys: delta time (i.e., call duration in s), average entropy (i.e., the amount of disorder for a typical spectrum slice of a call in bits), aggregate entropy (i.e., the overall disorder of a call in bits), peak frequency (i.e., the maximum frequency measured on a call in $\mathrm{kHz}$ ), peak time relative (i.e., the relative position of the peak frequency on a call (measure between 0 and 1)), low frequency (i.e., the lowest frequency of a call in $\mathrm{kHz}$ ), high frequency (i.e., the highest frequency of a call in $\mathrm{kHz}$ ), delta frequency (i.e., the frequency range between 'low frequency' and 'high frequency' in $\mathrm{kHz}$ ) and centre time relative (i.e., the relative position of the point where a call is divided into two parts of equal energy (measure between 0 and 1)).

For the subsequent call classification, we selected only good quality calls (i.e., free of interference and with low background noise). We replaced outliers by the means (for details on outlier identification and sample sizes, see Online Resource 1, Table S3). We then removed highly correlated acoustic parameters (Pearson correlation test; coefficient $>0.8$ ) and kept the following ones: delta time, average entropy, peak time relative, peak frequency, low frequency, high frequency and centre time relative. All non-correlated acoustic parameters were standardized prior to analysis.

\section{Call classification}

We carried out a permutated discriminant function analysis (pDFA; R function by Roger Mundry, based on the lda function of the 'MASS' R package version 7.5-53; Venables and Ripley 2002; Mundry and Sommer 2007) to check the classification in the three attributed call types (i.e., 'kroo', 'tcha', 'kow') with call type as test variable and the trial ID as control factor (pDFA1). The pDFA allows to control for the non-independence of data due to repeated measurements (i.e., control factor), unlike conventional DFAs, and is now commonly used for acoustic analyses of animal vocal repertoires (e.g., Collier et al. 2020; Keenan et al. 2020). We also analysed inter-individual variation by running another pDFA (pDFA2) on $N=6$ different males (i.e., six different trials, selected based on home range estimates and time of recording; see Online Resource 1, Table S4), who produced a minimum of 22 'kroo' calls of good acoustic quality (range: $22-55$ calls). For this analysis, we used the trial ID as the test variable and the playback stimulus as a control factor (i.e., type of danger or type of Campbell's monkey calls; see 
Online Resource 1, Table S4). The two call types 'tcha' and 'kow' were almost always given as combinations consisting of one 'tcha' followed by one 'kow' (mean time interval between two calls $=0.09 \mathrm{~s}, \mathrm{SD}=0.04 \mathrm{~s}$, range $=0.02-0.19 \mathrm{~s}$ ). We recorded a total of $N=90$ combinations of 'tcha' followed by 'kow', $N=4$ single 'tcha', and $N=9$ single 'kow', so we decided to analyse them as one combined call (i.e., 'tcha-kow'). Single 'tcha' and 'kow' were produced across contexts and, due to small sample sizes, we were unable to investigate their production further in this study.

\section{Responses to dangers}

To test if 'kroos' contained subtle, context-specific acoustic variation, we first explored whether this alarm call type could be discriminated depending on the type of danger. We ran a pDFA (pDFA3) with the 'kroos' produced in response to the leopard growls ( $N=160$ 'kroos' over $N=12$ playback trials), eagle shrieks ( $N=60$ 'kroos' over $N=4$ playback trials) and falling trees $(N=120$ 'kroos' over $N=5$ playback trials). To avoid ambiguity, we only considered playback trials without Campbell's monkey vocal response. We used the type of danger (leopard/eagle/tree) as test variable and the trial ID as control factor.

We ran several generalized linear models (GLMs) to explore the effects of playback stimuli (i.e., leopard, eagle, falling tree) and Campbell's monkey vocal responses on lesser spot-nosed monkey call production. For the following GLMs (GLM1 to 5), we used the interaction between the type of danger (leopard/eagle/falling tree) and the Campbell's monkey vocal responses (yes/no) as test variables. We first tested the response probability by running a GLM (GLM1) with a binomial error structure and logit link function, with the vocal response (yes/no) as response variable. We then analysed the production of the specific call types ('kroo' and 'tcha-kow') and thus only considered trials with vocal responses to test which call type was produced first. We tested this by running a GLM (GLM2) with a binomial error structure and logit link function, with the first call type ('kroo'/'tcha-kow') as response variable. Since 'kroos' were produced in all contexts, we explored what factors determined calling effort. We tested this by running a GLM (GLM3) with a negative binomial error structure and a log link function, with the total number of 'kroo' produced during the trial as response variable. For this analysis, we excluded trials where the male Campbell's monkey started to vocalise after the male lesser spot-nosed monkey produced his first 'kroo' to avoid ambiguity. In another GLM (GLM4) with a gamma distribution and inverse link function, we analysed the initial call rate (three first 'kroos' per time in s) as response variable. Here again, we excluded trials where the male Campbell's monkey started to vocalise between the male lesser spot-nosed monkey first and third 'kroo' to avoid ambiguity during call production. In a final GLM (GLM5) with a gamma distribution and inverse link function, we analysed the response latency (s) as response variable, determined as the time interval between the beginning of the stimulus and the first 'kroo' response.

\section{Responses to Campbell's monkey alarm calls}

We ran a second series of analyses, analogous to the previous ones, this time with the male Campbell's monkeys alarm calls as playback stimuli ('hok', 'krak' and 'boom'). We controlled for variations within each playback type (i.e., number of calls, intermediate intervals; Online Resource, Table S1) by using generalised linear mixed models (GLMMs) with GLMM1-GLMM5 corresponding to previous GLM1 to 5, with the same distributions and response variables, respectively. We used the Campbell's monkey alarm call playbacks ('hok'/ 'krak'/ 'boom') as test variables and the playback variation as random factor for all GLMMs. To prevent a singular model fit in GLMM1, we used the bglmer function of the 'blme' R package version 1.0-5 (Chung et al. 2013) with a null covariance prior and a normal fixed effect prior.

For all GLMs and GLMMs, the significance of the tested variables was established using the Anova function in the 'car' R package version 3.0-10 (Fox and Weisberg 2019). When the interaction between the type of danger and the Campbell's monkey vocal response (for the GLMs) or the Campbell's monkey alarm playbacks (for the GLMMs) was significant, we carried out Tukey post hoc multiple comparison tests using the function glht of the 'multcomp' $\mathrm{R}$ package version 1.4-15 (Hothorn et al. 2008) to see which combinations were significantly different from each other. Model assumptions were checked using Q-Q and residual plots.

All analyses were done in R v1.3.1093 (R Core Team 2020).

\section{Results}

\section{Call classification}

Male lesser spot-nosed monkeys produced three distinct calls, 'kroo', 'tcha' and 'kow', and the pDFA1 confirmed that the calls could be reliably classified using our set of acoustic parameters $(N=772$ 'kroos', $N=50$ 'tchas', $N=54$ 'kows', $p=0.002$, correctly cross-classified $=77 \%$, expected $=35 \%$; Fig. 1). However, we found no pDFA evidence for interindividual acoustic variation in 'kroo' production (pDFA2, $N=204$ 'kroos' over $N=6$ males lesser spot-nosed monkeys, $p=0.52$ ). We also found no pDFA evidence for context-specific acoustic variation, regardless of the type of 
Fig. 1 Male lesser spot-nosed monkey 'kroo' (yellow), 'tcha' (pink) and 'kow' (blue) calls, plotted in principal component space with corresponding spectrograms. $\mathrm{PC} 1$ and PC2 accounted for $57.4 \%$ of variance. Principal component analyses were calculated with $P C A$ function from the 'FactoMineR' R package 2.3 (Lê et al. 2008); spectrograms were extracted from Raven Pro 1.5.0 and contrasted with Adobe Photoshop 21.0.3

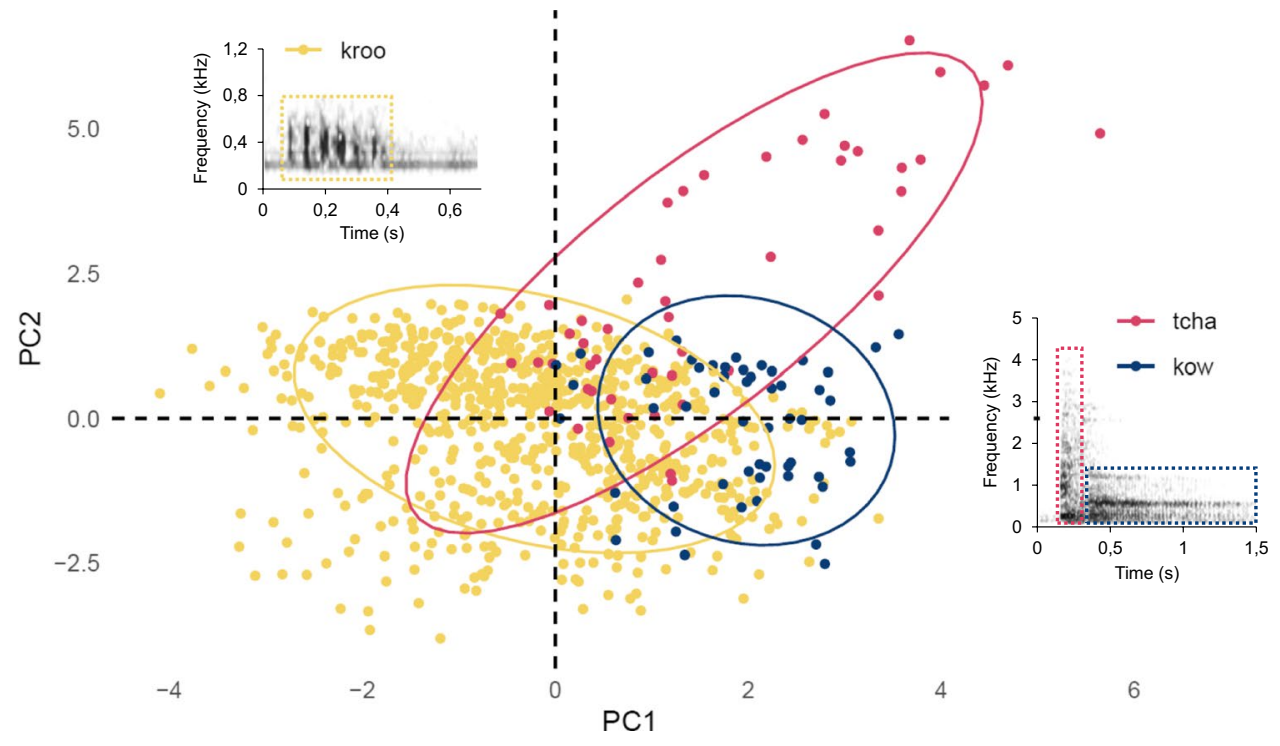

danger (leopard/eagle/falling tree; pDFA3; $N=345$ 'kroos', $p=0.55$; Fig. 2).

\section{Responses to dangers}

We ran $N=65$ playback trials on lesser spot-nosed monkey groups to investigate how males used their calls (i.e., 'kroo' and combined 'tcha-kow' calls) in response to common dangers (eagle: $N=19$; leopard: $N=31$; falling trees: $N=15$ ). We found that, if Campbell's monkeys did not alarm call first, males only produced 'kroos', regardless of the type of simulated danger (Fig. 3a). Conversely, if Campbell's monkeys gave alarm calls first, males produced either 'kroos' to all three dangers or 'tcha-kows' to eagles and falling trees and exceptionally both 'kroos' and 'tcha-kows' to falling trees (Fig. 3a).

Generally, we found that calling responses were only weakly affected by the type of danger, but strongly by the alarm calling behaviour of associated Campbell's monkeys. In particular, the overall probability of calling ('kroo' or 'tcha-kow') was significantly affected by the interaction between the type of danger (i.e., eagle, leopard, falling tree) and Campbell's monkey alarm calling (i.e., whether they called or not) (GLM1: ANOVA: $\mathrm{Chi}^{2}=15.379, p<0.001$; Fig. 3a). Post hoc pairwise comparisons did not show a significant difference between the different combinations of contexts (see Online Resource 1, Table S5). The type of the first call produced was not affected by the type of danger but by whether or not there was prior Campbell's monkey alarm
Fig. 2 Male Campbell's and lesser spot-nosed monkey alarm calls to eagles, leopards and falling trees, plotted in principal component space. $\mathrm{PC} 1$ and PC2 accounted for $63.5 \%$ of variance and segregate the three Campbell's monkey alarm calls, but not the lesser spot-nosed monkey 'kroo' alarm calls

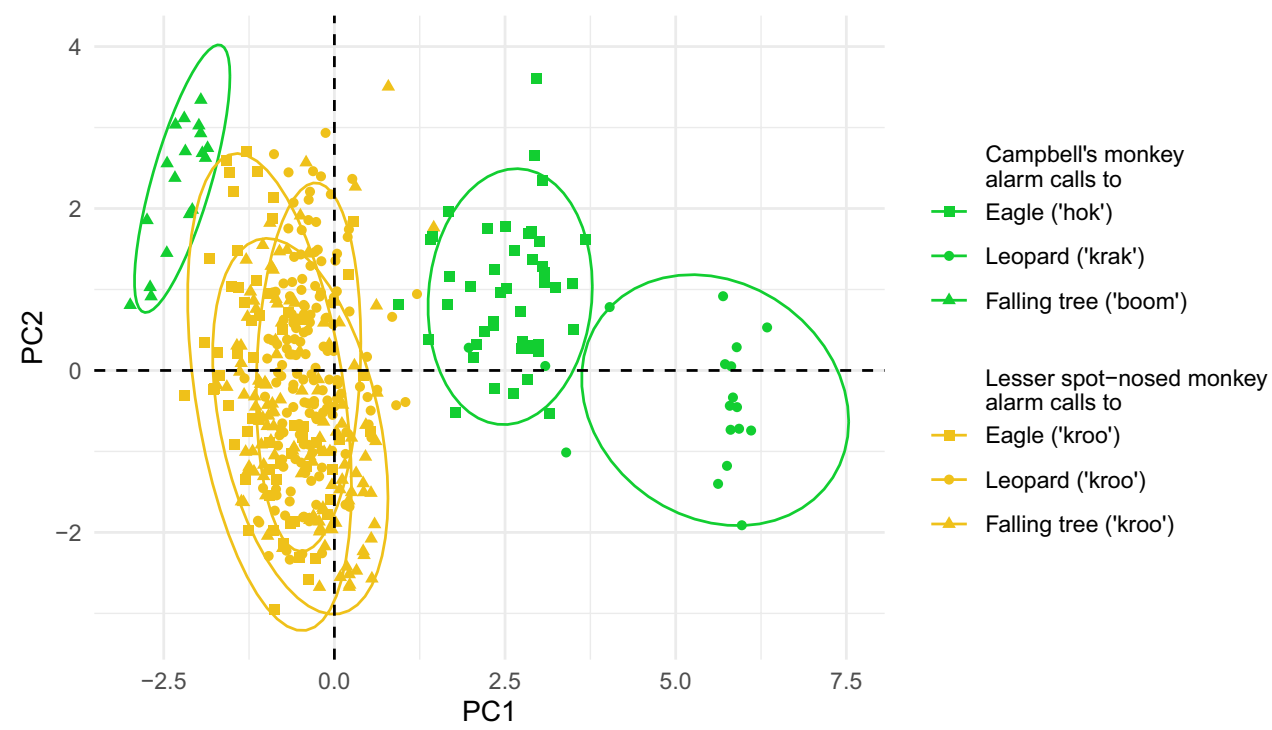



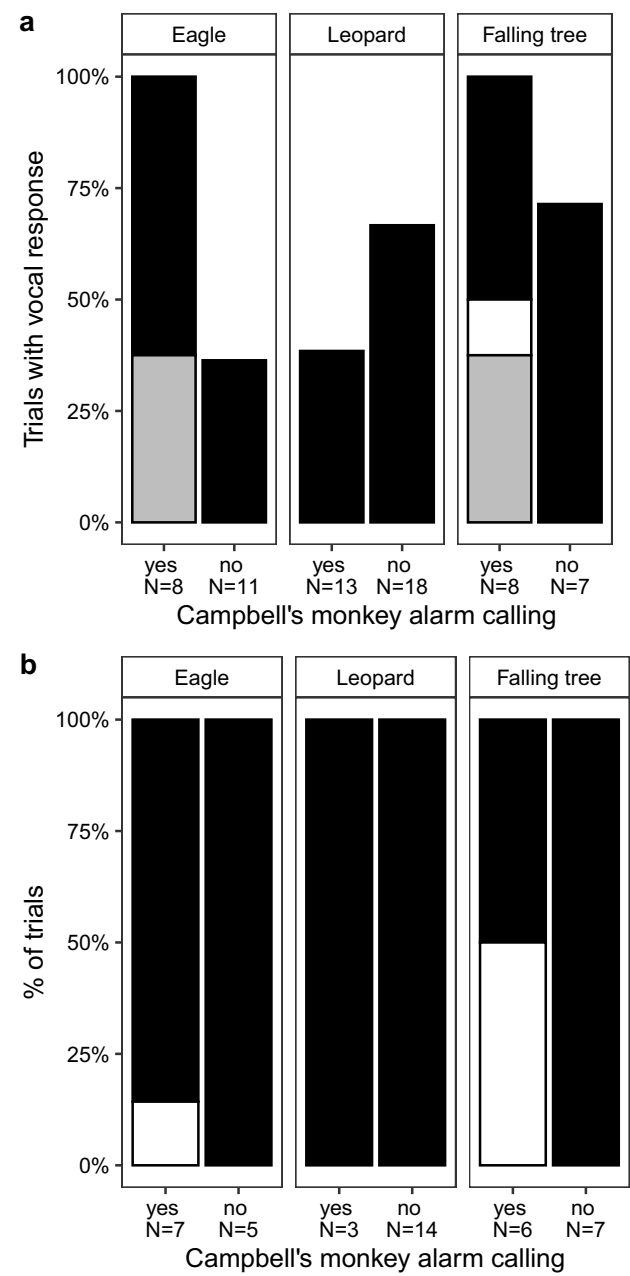

Fig. 3 Male lesser spot-nosed monkey a call production, b first call produced, c number of 'kroo' produced, $\mathbf{d}$ initial rate of 'kroo' production and e response latency to the first 'kroo' produced, in response to eagle, leopard and falling tree playbacks and depending

calling (GLM2, ANOVA: $\mathrm{Chi}^{2}=6.87, p=0.009$; Fig. 3b). In particular, 'tcha-kows' were produced only after Campbell's monkey alarm calls.

Similarly, when analysing 'kroo' production efforts, we found no effect of the type of danger but a clear effect of Campbell's monkey alarm calling on the number of 'kroos' produced, the rate of the three first 'kroos' and the response latency between the start of the stimulus and the first 'kroo' ( $N$ 'kroo': GLM3, ANOVA: $\mathrm{Chi}^{2}=5.262, p=0.022$, Fig. 3c; initial 'kroo' rate: GLM4, ANOVA: $\mathrm{Chi}^{2}=4.990$, $p=0.026$, Fig. 3d; 'kroo' response latency: GLM5, ANOVA: $\mathrm{Chi}^{2}=18.498, p<0.001$; Fig. 3e).

\section{Responses to Campbell's monkey alarm calls}

In the second experiment, we carried out $N=45$ trials to investigate how male lesser spot-nosed monkeys c
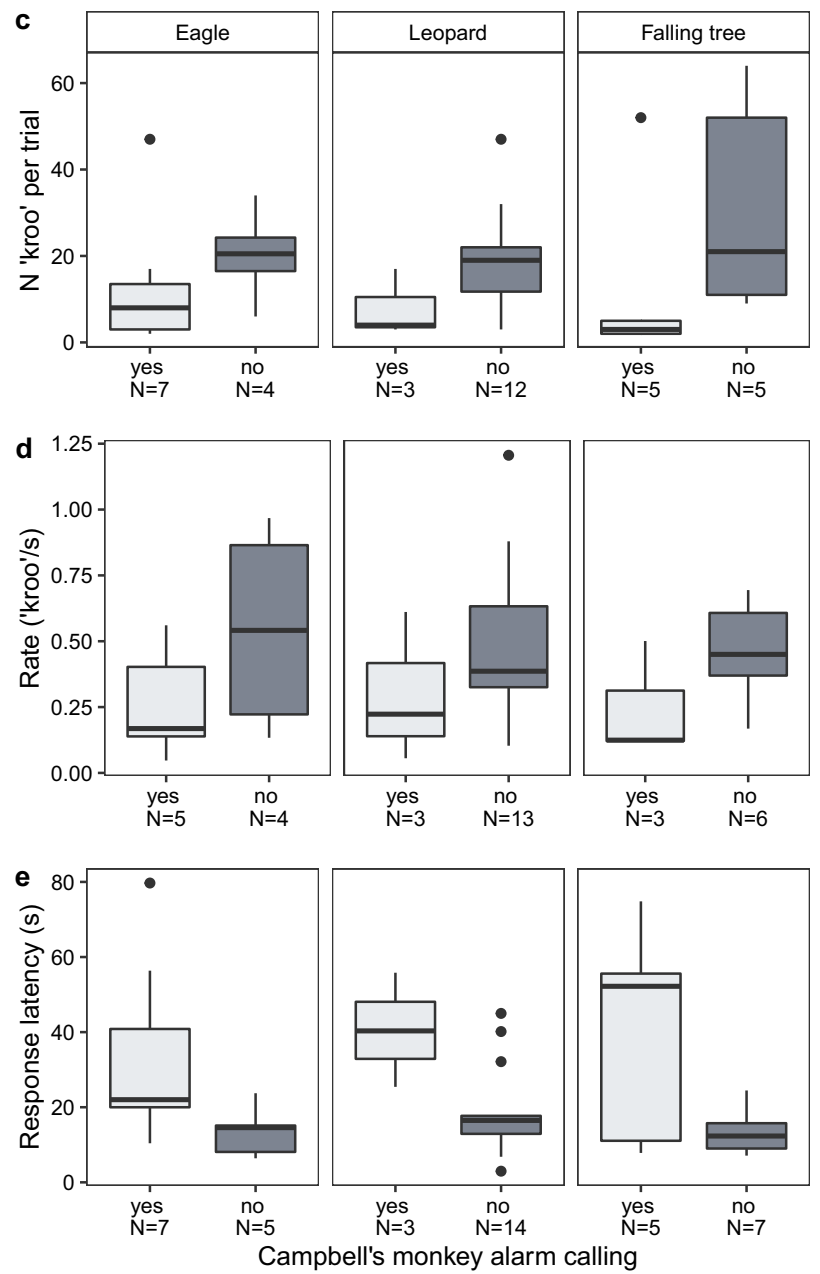

on the alarm calling behaviour of associated male Campbell's monkeys. Boxes show the inter quartile range, with the central line depicting the median, the whiskers indicating quantiles $(0.025$ and 0.975$)$ and outliers

used their calls in response to Campbell's monkey alarm calls to eagles ('hok', $N=11$ ), leopards ('krak', $N=14$ ) and non-predatory dangers ('boom', $N=20$ ). Again, we found that the type of Campbell's monkey alarm calls did not affect the overall call response probability (GLMM1, ANOVA: $\mathrm{Chi}^{2}=5.335, p=0.069$; Fig. 4 a) although it did affect the type of first call produced (GLMM2, ANOVA: $\mathrm{Chi}^{2}=12.894, p=0.002$; Fig. 4b). In particular, to Campbell's monkey 'booms', male lesser spot-nosed monkeys produced mostly 'tcha-kows' whereas, to Campbell's monkey 'hoks' or 'kraks', they uniformly responded with 'kroos' (pairwise post hoc comparisons 'boom' vs. 'hok': $\beta=4.367, \mathrm{SE}=1.293, Z=3.377, p=0.002$; 'boom' vs. 'krak': $\beta=5.245, \mathrm{SE}=2.061, Z=2.544, p=0.028$; 'hok' vs.' 'krak'; $\beta=-0.878, \mathrm{SE}=1.910, Z=-0.460, p=0.887$ ).

The 'kroo' production effort to the three Campbell's monkey alarm calls varied in number of 'kroo' produced 
Fig. 4 Male lesser spot-nosed monkey a call production, $\mathbf{b}$ first call produced and $\mathbf{c}$ number of 'kroo' produced, in response to male Campbell's monkey alarm calls playbacks (with associated contexts of production). Boxes show the inter quartile range, with the central line depicting the median, the whiskers indicating quantiles (0.025 and 0.975) and outliers. $* p<0.01$

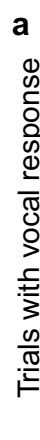
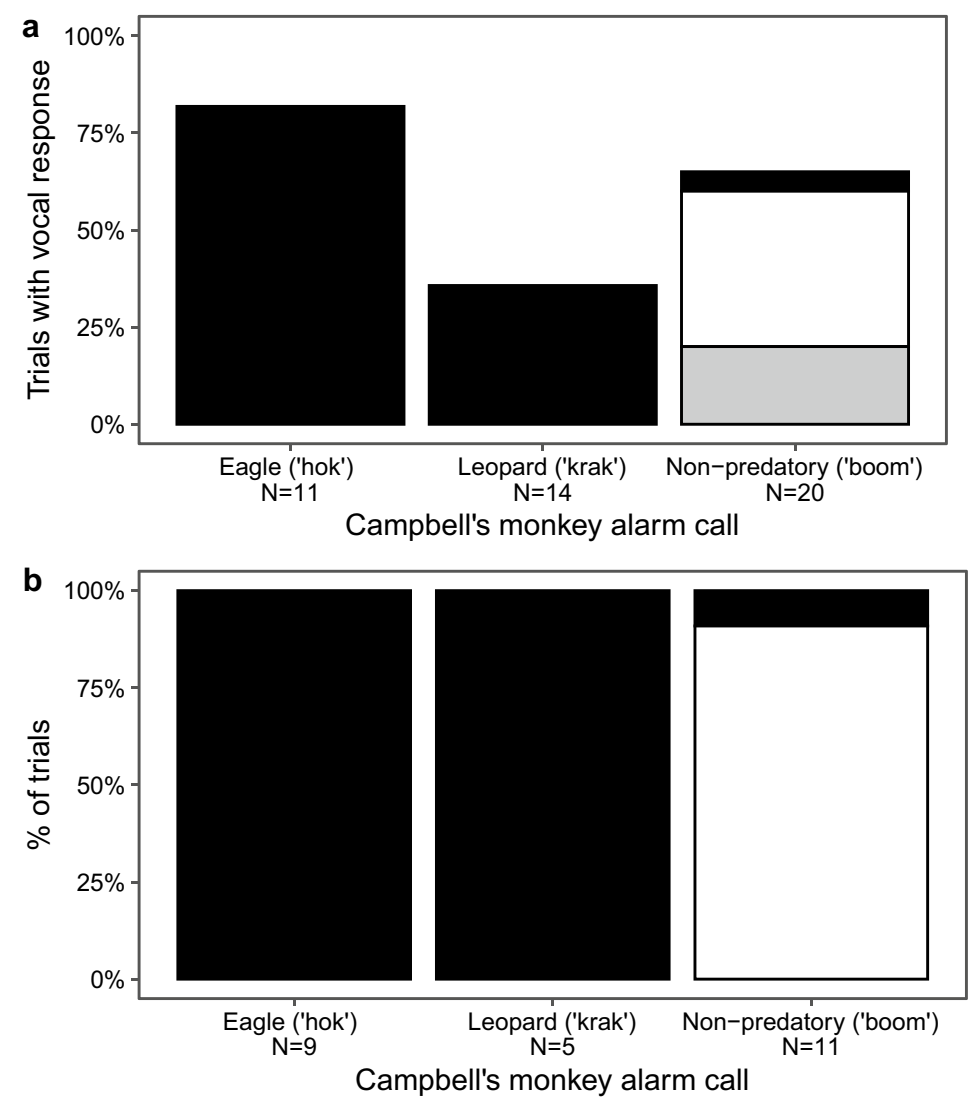

First call produced
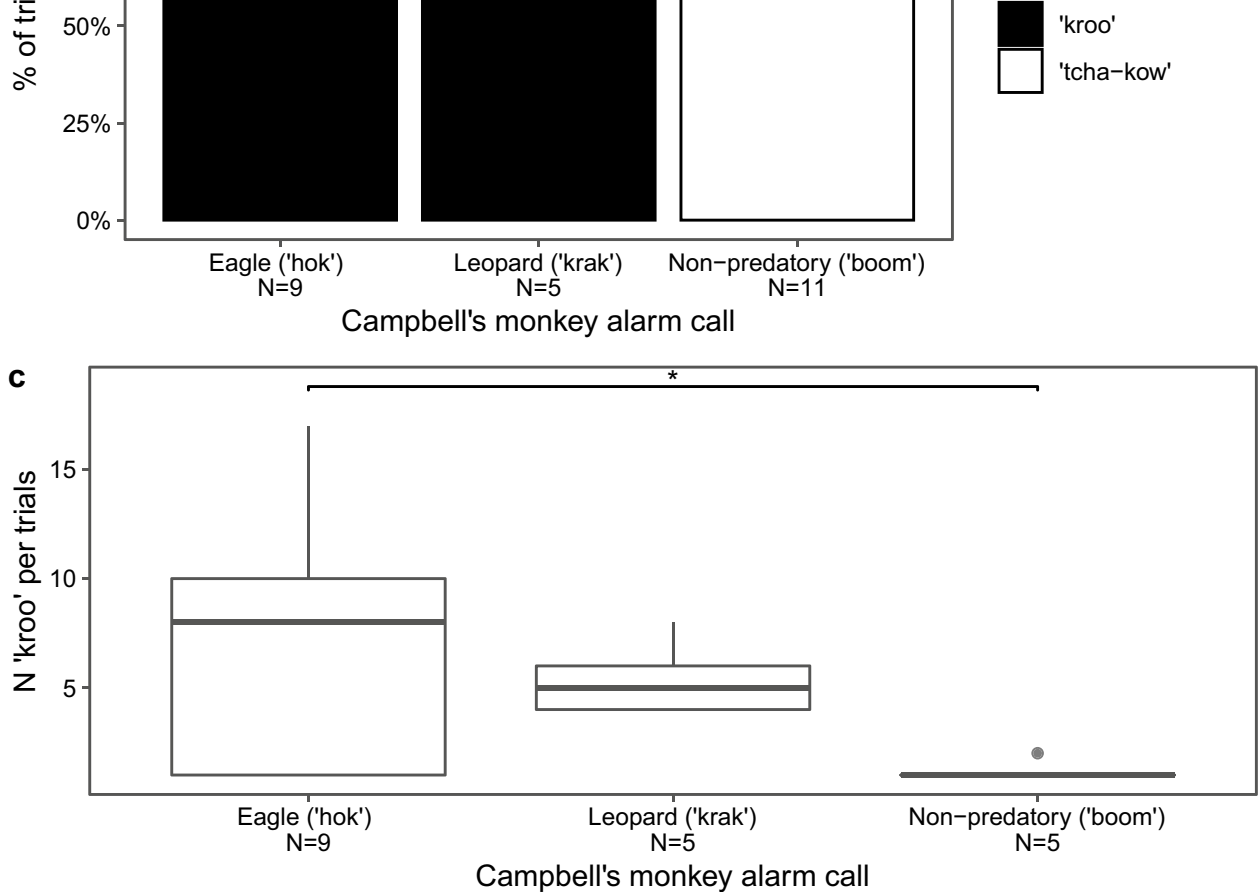

(GLMM3, ANOVA: $\mathrm{Chi}^{2}=7.837, p=0.020$; post hoc comparisons 'hok' vs. 'boom': $\beta=-1.686, \mathrm{SE}=0.606$, $Z=-2.783, p=0.014$; 'krak' vs. 'boom': $\beta=-1.486$, $\mathrm{SE}=0.654, Z=-2.274, p=0.058$; 'hok' vs. 'krak': $\beta=-0.199, \mathrm{SE}=0.452, Z=-0.441, p=0.897$; Fig. 4c) but not in the initial 'kroo' rate (GLMM4, ANOVA: $\mathrm{Chi}^{2}=2.114, p=0.146$ ) nor in the 'kroo' response latency (GLMM5, ANOVA: $\mathrm{Chi}^{2}=5.291, p=0.071$ ).

Finally, we observed that when lesser spot-nosed monkeys produced 'tcha-kows' in response to Campbell's monkey 'booms', they consistently replied with a $10 \mathrm{~s}$ latency (mean $=10.0 \mathrm{~s}, \mathrm{SD}= \pm 1.06 \mathrm{~s}$ ) following the first 'boom'. In $54.5 \%$ of the trials $(N=11)$, males produced a second 'tcha-kow' (mean time interval between the two 'tchakow' $=0.27 \mathrm{~s}, \mathrm{SD}= \pm 0.23 \mathrm{~s}$ ).

\section{Discussion}

In this study, we investigated the alarm call system of lesser spot-nosed monkeys and the influence of Campbell's monkey vocal behaviour. Lesser spot-nosed and Campbell's monkeys form robust mix-species associations, forage mainly in the lower canopy and have the same social organisation (McGraw and Rowe 1996; Buzzard 2006, 2010; McGraw et al. 2007; Daegling 2020). We first established the male 
lesser spot-nosed monkey call repertoire when encountering three types of danger (eagle, leopard and falling tree) and corresponding Campbell's monkey alarm call, and identified three call types, 'kroo', 'tcha' and 'kow', the latter mainly produced as combinations ('tcha-kow'; see Oates (1985) for alternative terminology). In playback experiments, we established that 'kroos' were given to any type of danger (eagles, leopards, falling trees) and also to male Campbell's monkey predator-specific alarm calls ('hok', 'krak'), but not to their calls produced in non-predatory contexts ('boom'), suggesting that 'kroos' are equal to the 'purring' call reported by Rowe (1996).

We found no evidence for predator-specific differences in 'kroo' calling efforts, suggesting that 'kroo' production is unaffected by predator type. Equally surprising was the fact that we failed to find any evidence for acoustic variants within the 'kroo' call, neither in terms of predatorspecificity nor in terms of individual identity. This was also found experimentally when we simulated danger with male Campbell's monkey context-specific alarm calls. Again, male lesser spot-nosed monkeys responded uniformly by producing 'kroos', regardless of alarm call types, and 'tchakows' after Campbell's monkey 'booms'. This result is in contrast with most primate species that have been investigated so far in similar ways (e.g., Diana monkeys, Zuberbühler et al. 1997; Campbell's monkeys, Zuberbühler 2001; tamarins, Kirchhof and Hammerschmidt 2006; vervet monkeys, Seyfarth et al. 1980; titi monkeys, Berthet et al. 2018; tufted capuchin monkeys (Sapajus paella), Wheeler 2010; blue monkeys, Mielke and Zuberbühler 2013; putty-nosed monkeys, Price et al. 2009; green monkeys (Chlorocebus sabaeus), Price and Fischer 2014) and requires explanation.

\section{'Kroo' calls as general alarms}

Lesser spot-nosed monkeys produce 'kroo' calls to a variety of dangers and thus qualify as general alarm or alert calls (Dezecache and Berthet 2018). General alarm calls have already been described for other primate and non-primate species, such as Gunnison's prairie dogs (Cynomys gunnisoni) 'bark' calls for different predator types (Loughry et al. 2019) or woolly monkey (Lagothrix lagothricha) 'eolk' calls to predatory and non-predatory disturbances (Casamitjana 2002). Different functional explanations have been offered for general alarm calls (Dezecache and Berthet 2018), such as providing callers with the option to create a semantic contrast to predator-specific alarm calls, typically aerial alarm calls (e.g., dwarf mongoose (Helogale parvula), Collier et al. 2020; putty-nosed monkeys, Price et al. 2009), or to issue a behavioural imperative (e.g., 'hide!') to warn other group members or, in exceptional cases, deceptively, to gain access to food (Flower et al. 2014).
In our study, we did not find any evidence for predatorspecific alarm calls. Instead, lesser spot-nosed monkeys used the same alarm call type, 'kroo', to any type of danger with only one further (combined) call, 'tcha-kow', given mainly in response to Campbell's monkey calls produced in nonpredatory contexts, 'boom' calls (Fig. 3a, b). In sum, lesser spot-nosed monkeys appear to have an alarm call system with a rather limited semantic capacity, not able to distinguish between predatory and non-predatory disturbances or event categories. Another possibility could be Dezecache and Berthet's imperative hypothesis (2018), i.e., that ' $k r o o$ ' calls function as instructions to other group members (e.g., 'look around!'). In any case, more detailed behavioural observations are needed to understand the mechanisms of call production and receivers perception, ideally also from other study populations.

It is also possible that our acoustic analyses were simply not fine-scaled enough to pick up acoustic variation related to the event. If this was the case, our analyses demonstrate that acoustic variation in this species' alarm calls would be considerably more subtle compared to what is normally seen in primate alarm calling (Fig. 2), especially regarding eagle alarms (Gautier and Gautier 1977). In order to address this hypothesis, it would be necessary to carry out playback experiments, to test whether recipients react differently to calls recorded to different predator types (e.g., Zuberbühler 2000). Furthermore, acoustic variations in alarm calls might not be associated with the type of danger but rather with other contextually relevant cues, such as predator behaviours (e.g., Griesser 2008), sizes (e.g., Templeton 2005), colours (Slobodchikoff et al. 2009), attack directions (e.g., Berthet et al. 2019) or response urgencies (e.g., Lemasson et al. 2010; Townsend et al. 2012; Murphy et al. 2013). Finally, and although we consider this also unlikely, future research should verify if any of the above information is encoded at the sequence level, similar to what has been described for Guereza colobus monkeys (Colobus guereza, Schel et al. 2010).

\section{Eavesdropping and mixed-species associations between lesser spot-nosed and Campbell's monkeys}

A second major finding of this study was that lesser spotnosed monkey alarm calling was heavily influenced by Campbell's monkeys. For the 'kroo', the general pattern was that, if a male Campbell's monkey called, the male lesser spot-nosed monkey reduced his own calling efforts compared to when Campbell's monkeys did not call. The influence of male Campbell's monkeys was even more striking when analysing 'tcha-kow' call production. Here, our results showed that this call type was produced, in almost all cases, about $10 \mathrm{~s}$ after the first Campbell's monkey 'boom' call and hardly ever in other situations. 
As mentioned, lesser spot-nosed monkeys spend most of their time in mixed-species associations with other primates, mostly Campbell's monkeys. Such associations can provide predator avoidance and foraging advantages (Stensland et al. 2003) and vocal behaviour is a key mediator of any such benefits (Magrath et al. 2015). As proposed by Goodale et al. (2010), conspicuous vocal behaviour by one species can serve as a driving force in the formation or maintenance of mixed-species groups. For instance, in mixed-species groups of tamarins, the long calls of one species can cause vocal responses and approaches by the other (Windfelder 2001), suggesting that these calls could function to recruit heterospecifics (Goodale et al. 2020).

Interspecies call recognition has mostly been studied with alarm calls (for review, see Magrath et al. 2015, 2020). The process is best referred to as 'eavesdropping', by which one species extracts information from another species' vocal behaviour and then reacts appropriately, mostly in the context of predator avoidance and foraging (Goodale et al. 2010). Eavesdropping is widespread with a large body of evidence in primates (Zuberbühler et al. 1997; Ramakrishnan and Coss 2000; Fichtel 2008; Walton and Kershenbaum 2019) but also in birds ( Fallow and Magrath 2010; Dawson Pell et al. 2018; Keen et al. 2020) and even reptiles. For example, non-vocal iguanas (Amblyrhynchus cristatus and Oplurus cuvieri) can discriminate mockingbird (Nesomimus parvulus) and paradise flycatcher (Terpsiphone mutate) alarm calls (Ito and Mori 2010; Vitousek et al. 2007). However, in many species, eavesdropping individuals respond with their own alarm calls to the calls of another species (Shriner 1998; Ramakrishnan and Coss 2000; Zuberbühler 2000; Rainey et al. 2004; Slater et al. 2004).

In our study, results suggest that lesser spot-nosed monkeys discriminated Campbell's monkey alarm calls, as males responded with 'kroos' to male Campbell's monkey eagle and leopard alarm calls and 'tcha-kows' to Campbell's monkey 'booms'. However, whether they also discriminated Campbell's monkey eagle ('hok') and leopard alarms ('krak') as predator-specific alarm calls cannot be decided by our data. Nevertheless, we found that lesser spot-nosed monkey calling efforts decreased if Campbell's monkeys alarm called compared to when they did not call. Overall, these calling patterns are compatible with the hypotheses that lesser spot-nosed monkeys benefit from an associated species to minimize their own exposure to predators by eavesdropping on their alarm calls.

The large majority of 'tcha-kows' were produced immediately after Campbell's monkey 'boom' calls, and only rarely after situations that elicited the 'boom' calls (i.e., mostly falling trees), suggesting that the calls did not primarily function to refer to a type of danger. Instead, we see two possible explanations. First, 'tcha-kows' were produced to secure associations with Campbell's monkeys. Both species form strong, semi-permanent associations (Buzzard 2010) and male calls function to mediate such relationships. Second, 'tcha-kows' were used as territorial defence to warn rival males and produced to benefit from the attention raised by the preceding Campbell's monkey 'booms', which travel over considerable distances (Zuberbühler 2004; McGraw et al. 2007). Moreover, if predators are attracted by such male loud calls, then male lesser spot-nosed monkeys can reduce the number of such events, by aligning their own calls with the calling of associated Campbell's monkeys, rather than calling independently. Further studies focusing on receiver and predator behaviour is needed to learn how they react to 'tcha-kow' calls with or without preceding Campbell's monkey 'boom' calls.

\section{Limitations of playback experiments}

Our study was based on a well-tried paradigm, simulating predator presence with acoustic cues. This approach is especially effective for species living in dense forest habitats, where individuals rely heavily on auditory information to learn about ongoing events in their vicinity. Although we have managed to collect samples from a large $50 \mathrm{~km}^{2}$ area of Taï National Park, our final sample size for each of the various conditions was relatively small, due to the difficulty of obtaining high quality and statistically independent recordings, a clear limitation to this study. In addition, playbacks are an incomplete way of investigating the mechanisms and function of animal vocal behaviour, unless they are complemented with careful, long-term behavioural observations. Also, simulating predator presence by acoustic means is suboptimal because the critical predator information is provided to everyone at the same time, which arguably makes warning others obsolete. Complementary experiments with realistic visual predator models would be needed to see if patterns change when predator information is administered individually.

\section{Conclusions}

We have analysed the alarm call behaviour of male lesser spot-nosed monkeys, a West African forest guenon exposed to high predation pressure from different predators. Contrary to the alarm systems of other Cercopithecus monkeys living in similar environments, we found no evidence for predator-specific alarm calls in this species. Instead, we found evidence for a general alarm call, 'kroo', given to all types of dangers (eagles, leopards and falling trees) and a more specialized call, 'tcha-kow', given presumably to form mix-group associations with Campbell's monkeys and possibly to repel sexual rivals. For both call types, production was heavily influenced by the calling behaviour of associated Campbell's monkeys, with a 
reduction of the 'kroo' calling effort when associated male Campbell's monkeys produced their own alarm calls and a temporarily tight, duet-like production of 'tcha-kows' in response to Campbell's monkey 'boom' calls. We concluded that male lesser spot-nosed monkeys adjust their call production presumably to reduce their own exposure to predators by eavesdropping on Campbell's monkeys and to secure mixed-species association.

Supplementary Information The online version contains supplementary material available at https://doi.org/10.1007/s00265-021-03053-w.

Acknowledgements We thank Ernest Kamy for assistance with data collection and all the other members of the Taï Monkey Project for their support. We thank Anderson Bitty and the staff of the Centre Suisse de Rercherches Scientifiques for logistic support and the Office Ivoirien des Parcs et Réserves (OIPR) for permission to conduct research in Taï National Park. We thank Virgile Manin and the staff of the Taï Chimpanzee Project (TCP) for support in the field. We thank Radu Slobodeanu and Gérard Kubryk for advice on statistical analyses, Mélissa Berthet for help with acoustic analyses and discussion, Steven Moran for comments and Redouan Bshary for discussion. We thank the editor and three anonymous reviewers for their valuable comments that improved the quality of our manuscript.

Author contribution ALF and KZ conceptualised the project, designed experiments and collected data; ALF and QG digitised KZ's recordings and designed the methodology for acoustic analyses; ALF coded the vocalisations; $\mathrm{AB}$ and ALF performed the statistical analyses; $\mathrm{AB}$, $\mathrm{ALF}, \mathrm{KZ}$ and QG wrote the paper; $\mathrm{KZ}$ raised financial support.

Funding Open Access funding provided by Université de Neuchâtel. The Taï Monkey Project has been partially funded by grants from the Swiss National Science Foundation (\#310030_185324; \#31003A_166458). ALF has been supported by a Willy Müller Award from the Centre Suisse de Recherches Scientifiques en Côte d'Ivoire and the University of Neuchâtel. AB and QG have been funded by the University of Neuchâtel and the Swiss National Science Foundation (\#31003A_166458). KZ is supported by 'NCCR Evolving Language', Swiss National Science Foundation Agreement \#51NF40_180888.

Data availability The datasets analysed during the current study are available in the following Figshare repository: https://figshare.com/ projects/Lesser_spot-nosed_monkeys_coordinate_alarm_call_produ ction_with_associated_Campbell_s_monkeys/98576.

Code availability The code used for this study is available in the following Figshare repository: https://figshare.com/projects/Lesser_spotnosed_monkeys_coordinate_alarm_call_production_with_associated_ Campbell_s_monkeys/98576.

\section{Declarations}

Ethics approval This work was conducted under the approval of the Ivorian Ministry of Scientific Research and the Ivorian Office of Parks and Reserves for access to the Taï National Park. No further approval from the ethics committee for involving animals in this study was required. The use of wild animals in this research adheres to the guidelines set forth by the Association for the Study of Animal Behaviour.

Consent to participate Not applicable.
Consent for publication Not applicable.

Competing interests The authors declare no competing interests.

Open Access This article is licensed under a Creative Commons Attribution 4.0 International License, which permits use, sharing, adaptation, distribution and reproduction in any medium or format, as long as you give appropriate credit to the original author(s) and the source, provide a link to the Creative Commons licence, and indicate if changes were made. The images or other third party material in this article are included in the article's Creative Commons licence, unless indicated otherwise in a credit line to the material. If material is not included in the article's Creative Commons licence and your intended use is not permitted by statutory regulation or exceeds the permitted use, you will need to obtain permission directly from the copyright holder. To view a copy of this licence, visit http://creativecommons.org/licenses/by/4.0/.

\section{References}

Arnold K, Zuberbühler K (2006) The alarm-calling system of adult male putty-nosed monkeys, Cercopithecus nictitans martini. Anim Behav 72:643-653. https://doi.org/10.1016/j.anbehav. 2005.11.017

Baker MC, Becker AM (2002) Mobbing calls of black-capped chickadees: effects of urgency on call production. Wilson Bull 114:510-516

Berthet M, Mesbahi G, Pajot A, Cäsar C, Neumann C, Zuberbühler K (2019) Titi monkeys combine alarm calls to create probabilistic meaning. Sci Adv 5:eaav3991. https://doi.org/10.1126/sciadv. aav3991

Berthet M, Neumann C, Mesbahi G, Cäsar C, Zuberbühler K (2018) Contextual encoding in titi monkey alarm call sequences. Behav Ecol Sociobiol 72:8. https://doi.org/10.1007/s00265-017-2424-z

Boesch C (1994) Cooperative hunting in wild chimpanzees. Anim Behav 48:653-667. https://doi.org/10.1006/anbe.1994.1285

Boesch C, Boesch H (1989) Hunting behavior of wild chimpanzees in the Taï National Park. Am J Phys Anthropol 78:547-573. https:// doi.org/10.1002/ajpa.1330780410

Buzzard PJ (2010) Polyspecific associations of Cercopithecus campbelli and $C$. petaurista with $C$. diana: what are the costs and benefits? Primates 51:307-314. https://doi.org/10.1007/ s10329-010-0203-9

Buzzard PJ (2006) Ecological partitioning of Cercopithecus campbelli, C. petaurista, and C. diana in the Taï Forest. Int J Primatol 27:529-558. https://doi.org/10.1007/s10764-006-9022-7

Candiotti A, Zuberbühler K, Lemasson A (2012) Convergence and divergence in Diana monkey vocalizations. Biol Lett 8:382-385. https://doi.org/10.1098/rsbl.2011.1182

Caro TM (1986) The functions of stotting: a review of the hypotheses. Anim Behav 34:649-662. https://doi.org/10.1016/S00033472(86)80051-3

Casamitjana J (2002) The vocal repertoire of the woolly monkey Lagothrix lagothricha. Bioacoustics 13:1-19. https://doi.org/10.1080/ 09524622.2002.9753483

Cäsar C, Byrne RW, Hoppitt W, Young RJ, Zuberbühler K (2012) Evidence for semantic communication in titi monkey alarm calls. Anim Behav 84:405-411. https://doi.org/10.1016/j.anbeh av.2012.05.010

Chapman CA, Chapman LJ (1996) Mixed-species primate groups in the kibale forest: ecological constraints on association. Int J Primatol 17:31-50. https://doi.org/10.1007/BF02696157 
Chapman CA, Chapman LJ (2000) Interdemic variation in mixed-species association patterns: common diurnal primates of Kibale National Park, Uganda. Behav Ecol Sociobiol 47:129-139. https://doi.org/10.1007/s002650050003

Chung Y, Rabe-Hesketh S, Dorie V, Gelman A, Liu J (2013) A nondegenerate penalized likelihood estimator for variance parameters in multilevel models. Psychometrika 78:685-709. https://doi.org/ 10.1007/s11336-013-9328-2

Collier K, Radford AN, Stoll S, Watson SK, Manser MB, Bickel B, Townsend SW (2020) Dwarf mongoose alarm calls: investigating a complex non-human animal call. Proc R Soc B 287:20192514. https://doi.org/10.1098/rspb.2019.2514

Cords M (1990) Vigilance and mixed-species association of some East African forest monkeys. Behav Ecol Sociobiol 26:297-300. https://doi.org/10.1007/BF00178323

Covey R, McGraw WS (2014) Monkeys in a West African bushmeat market: implications for Cercopithecid conservation in Eastern Liberia. Trop Conserv Sci 7:115-125. https://doi.org/10.1177/ 194008291400700103

Coye C, Ouattara K, Zuberbühler K, Lemasson A (2015) Suffixation influences receivers' behaviour in non-human primates. Proc $\mathrm{R}$ Soc B 282:20150265. https://doi.org/10.1098/rspb.2015.0265

Cunningham S, Magrath RD (2017) Functionally referential alarm calls in noisy miners communicate about predator behaviour. Anim Behav 129:171-179. https://doi.org/10.1016/j.anbehav. 2017.05.021

Dawson Pell FSE, Potvin DA, Ratnayake CP, Fernández-Juricic E, Magrath RD, Radford AN (2018) Birds orient their heads appropriately in response to functionally referential alarm calls of heterospecifics. Anim Behav 140:109-118. https://doi.org/10. 1016/j.anbehav.2018.04.010

Dezecache G, Berthet M (2018) Working hypotheses on the meaning of general alarm calls. Anim Behav 142:113-118. https://doi.org/ 10.1016/j.anbehav.2018.06.008

Eckardt W, Zuberbühler K (2004) Cooperation and competition in two forest monkeys. Behav Ecol 15:400-411. https://doi.org/10.1093/ beheco/arh032

Engesser S, Ridley AR, Townsend SW (2016) Meaningful call combinations and compositional processing in the southern pied babbler. Proc Natl Acad Sci U S A 113:5976-5981. https://doi.org/ 10.1073/pnas.1600970113

Fallow PM, Magrath RD (2010) Eavesdropping on other species: mutual interspecific understanding of urgency information in avian alarm calls. Anim Behav 79:411-417. https://doi.org/10. 1016/j.anbehav.2009.11.018

Fichtel C (2008) Ontogeny of conspecific and heterospecific alarm call recognition in wild Verreaux's sifakas (Propithecus verreauxi verreauxi). Am J Primatol 70:127-135. https://doi.org/10.1002/ ajp.20464

Fichtel C, Kappeler PM (2002) Anti-predator behavior of group-living Malagasy primates: mixed evidence for a referential alarm call system. Behav Ecol Sociobiol 51:262-275. https://doi.org/10. 1007/s00265-001-0436-0

Fichtel C, van Schaik CP (2006) Semantic differences in Sifaka (Propithecus verreauxi) alarm calls: a reflection of genetic or cultural variants? Ethology 112:839-849. https://doi.org/10.1111/j.14390310.2006.01239.x

Fischer J, Hammerschmidt K, Todt D (2010) Factors affecting acoustic variation in Barbary macaque (Macaca sylvanus) disturbance calls. Ethology 101:51-66. https://doi.org/10.1111/j.1439-0310. 1995.tb00345.x

Fischer J, Metz M, Cheney DL, Seyfarth RM (2001) Baboon responses to graded bark variants. Anim Behav 61:925-931. https://doi.org/ 10.1006/anbe.2000.1687
Flower TP, Gribble M, Ridley AR (2014) Deception by flexible alarm mimicry in an African bird. Science 344:513. https://doi.org/10. 1126/science. 1249723

Foerster S (2008) Two incidents of venomous snakebite on juvenile blue and Sykes monkeys (Cercopithecus mitis stuhlmanni and $C$. m. albogularis). Primates 49:300-303. https://doi.org/10.1007/ s10329-008-0098-x

Fox J, Weisberg S (2019) An $\{\mathrm{R}\}$ Companion to Applied Regression, version 3.0-10, https://socialsciences.mcmaster.ca/jfox/Books/ Companion/

Gamer M, Lemon J, Ian Fellows Puspendra Singh (2019) irr: Various Coefficients of Interrater Reliability and Agreement, R package version 0.84.1, https://CRAN.R-project.org/package $=$ irr

Gautier J-P, Gautier A (1977) Communication in old world monkeys. In: University I (ed) How animals communicate Sebeok TA. Press, Bloomington, pp 890-964

Goodale E, Beauchamp G, Magrath RD, Nieh JC, Ruxton GD (2010) Interspecific information transfer influences animal community structure. Trends Ecol Evol 25:354-361. https://doi.org/10. 1016/j.tree.2010.01.002

Goodale E, Ruxton GD, Beauchamp G (2019) Predator eavesdropping in a mixed-species environment: how prey species may use grouping, confusion, and the cocktail party effect to reduce predator detection. Front Ecol Evol 7:141. https://doi.org/10. 3389/fevo.2019.00141

Goodale E, Sridhar H, Sieving KE et al (2020) Mixed company: a framework for understanding the composition and organization of mixed-species animal groups. Biol Rev 95:889-910. https:// doi.org/10.1111/brv.12591

Graw B, Manser MB (2007) The function of mobbing in cooperative meerkats. Anim Behav 74:507-517. https://doi.org/10.1016/j. anbehav.2006.11.021

Griesser M (2008) Referential calls signal predator behavior in a groupliving bird species. Curr Biol 18:69-73. https://doi.org/10.1016/j. cub.2007.11.069

Griesser M (2009) Mobbing calls signal predator category in a kin group-living bird species. Proc R Soc Lond B 276:2887-2892. https://doi.org/10.1098/rspb.2009.0551

Grieves LA, Logue DM, Quinn JS (2014) Joint-nesting smooth-billed anis, Crotophaga ani, use a functionally referential alarm call system. Anim Behav 89:215-221. https://doi.org/10.1016/j. anbehav.2014.01.008

Heymann EW (2011) Coordination in primate mixed-species groups. In: Boos M, Kolbe M, Kappeler PM, Ellwart T (eds) Coordination in Human and Primate Groups. Springer, Heidelberg, pp 263-281

Hothorn T, Bretz F, Westfall P (2008) Simultaneous inference in general parametric. Biometrical J 50:346-363

Ito R, Mori A (2010) Vigilance against predators induced by eavesdropping on heterospecific alarm calls in a non-vocal lizard Oplurus cuvieri cuvieri (Reptilia: Iguania). Proc R Soc Lond B 277:1275-1280. https://doi.org/10.1098/rspb.2009.2047

Jenny D (2005) Hunting behaviour in West African forest leopards. Afr J Ecol 43:197-200. https://doi.org/10.1111/j.1365-2028. 2005.00565.x

Kane EE, McGraw WS (2017) Dietary variation in Diana monkeys (Cercopithecus diana): the effects of polyspecific associations. Folia Primatol 88:455-482. https://doi.org/10.1159/000484560

Keen SC, Cole EF, Sheehan MJ, Sheldon BC (2020) Social learning of acoustic anti-predator cues occurs between wild bird species. Proc R Soc B 287:20192513. https://doi.org/10.1098/rspb.2019. 2513

Keenan S, Mathevon N, Stevens JM, Nicolè F, Zuberbühler K, Guéry JP, Levréro F (2020) The reliability of individual vocal signature 
varies across the bonobo's graded repertoire. Anim Behav 169:921. https://doi.org/10.1016/j.anbehav.2020.08.024

Kershenbaum A, Blumstein DT, Roch MA et al (2016) Acoustic sequences in non-human animals: a tutorial review and prospectus. Biol Rev 91:13-52. https://doi.org/10.1111/brv.12160

Kirchhof J, Hammerschmidt K (2006) Functionally referential alarm calls in tamarins (Saguinus fuscicollis and Saguinus mystax) evidence from playback experiments. Ethology 112:346-354. https://doi.org/10.1111/j.1439-0310.2006.01165.x

Klump GM, Kretzschmar E, Curio E (1986) The hearing of an avian predator and its avian prey. Behav Ecol Sociobiol 18:317-323. https://doi.org/10.1007/BF00299662

Koné I, McGraw S, Gonedelé Bi S, Oates JF (2019) Cercopithecus diana: The IUCN Red List of Threatened Species 2019: e.T4245A92384250, https://doi.org/10.2305/IUCN.UK.20193.RLTS.T4245A92384250.en.

Lê S, Josse J, Husson F (2008) FactoMineR: an R package for multivariate analysis. J Stat Softw 25:1-18. https://doi.org/10.18637/ jss.v025.i01

Lemasson A, Ouattara K, Bouchet H, Zuberbühler K (2010) Speed of call delivery is related to context and caller identity in Campbell's monkey males. Naturwissenschaften 97:1023-1027. https://doi.org/10.1007/s00114-010-0715-6

Loughry WJ, Oeser M, Anderson CD, Hoogland JL (2019) The importance of individual variation in the alarm calls of Gunnison's prairie dogs. Anim Behav 150:59-68. https://doi.org/ 10.1016/j.anbehav.2019.01.019

Magrath RD, Haff TM, Fallow PM, Radford AN (2015) Eavesdropping on heterospecific alarm calls: from mechanisms to consequences: interspecific eavesdropping. Biol Rev 90:560-586. https://doi.org/10.1111/brv.12122

Magrath RD, Haff TM, Igic B (2020) Interspecific communication: gaining information from heterospecific alarm calls. In: Aubin $\mathrm{T}$, Mathevon N (eds) Coding Strategies in Vertebrate Acoustic Communication. Springer International Publishing, Cham, pp 287-314

Manser MB (2001) The acoustic structure of suricates' alarm calls varies with predator type and the level of response urgency. Proc R Soc Lond B 268:2315-2324

Matsuda Goodwin R, Gonedelé Bi S, Koné I (2019) Cercopithecus campbelli: The IUCN Red List of Threatened Species 2020: e.T136930A92374066, https://doi.org/10.2305/IUCN.UK. 2020-2.RLTS.T136930A92374066.en

Matsuda Goodwin R, Segniagbeto G, Wiafe E, Osei D, Koné I, Gonedelé Bi S, Oates JF (2017) Cercopithecus petaurista. The IUCN Red List of Threatened Species 2020: e.T4225A17945536. International Union for Conservation of Nature, https://doi.org/10.2305/IUCN.UK.2020-2.RLTS.T4225 A17945536.en

McGraw S, Minhós T, Bersacola E, Ferreira da Silva MJ, Galat-Luong A, Gonedelé Bi S, Mayhew M, Oates JF, Starin ED (2020) Piliocolobus badius: The IUCN Red List of Threatened Species 2020: e.T161247840A161259430. https://doi.org/10.2305/IUCN.UK. 2020-1.RLTS.T161247840A161259430.en

McGraw WS (2000) Positional behavior of Cercopithecus petaurista. Int J Primatol 21:157-182. https://doi.org/10.1023/A:10054 83815514

McGraw WS, Daegling DJ (2020) Diet, feeding behavior, and jaw architecture of Taï monkeys: Congruence and chaos in the realm of functional morphology. Evol Anthropol 29:14-28. https://doi. org/10.1002/evan.21799

McGraw WS, Zuberbühler K (2008) Socioecology, predation, and cognition in a community of West African monkeys. Evol Anthropol 17:254-266. https://doi.org/10.1002/evan.20179
McGraw WS, Zuberbühler K, Noë R (2007) Monkeys of the Taï forest: an African primate community. Cambridge University Press, Cambridge

Mielke A, Zuberbühler K (2013) A method for automated individual, species and call type recognition in free-ranging animals. Anim Behav 86:475-482. https://doi.org/10.1016/j.anbehav.2013.04. 017

Mitani M (1991) Niche overlap and polyspecific associations among sympatric cercopithecids in the campo animal reserve, Southwestern Cameroon. Primates 32:137-151. https://doi.org/10. 1007/BF02381172

Mourthé IMC, Guedes D, Fidelis J, Boubli JP, Mendes SL, Strier KB (2007) Ground use by northern muriquis (Brachyteles hypoxanthus). Am J Primatol 69:706-712. https://doi.org/10.1002/ajp. 20405

Mundry R, Sommer C (2007) Discriminant function analysis with nonindependent data: consequences and an alternative. Anim Behav 74:965-976. https://doi.org/10.1016/j.anbehav.2006.12.028

Murphy D, Lea SEG, Zuberbühler K (2013) Male blue monkey alarm calls encode predator type and distance. Anim Behav 85:119125. https://doi.org/10.1016/j.anbehav.2012.10.015

Oates JF (1985) The Nigerian Guenon, Cercopithecus erythrogaster: ecological, behavioral, systematic and historical observations. Folia Primatol 45:25-43. https://doi.org/10.1159/000156189

Ouattara K, Lemasson A, Zuberbühler K (2009a) Campbell's monkeys concatenate vocalizations into context-specific call sequences. Proc Natl Acad Sci U S A 106:22026-22031. https://doi.org/10. 1073/pnas.0908118106

Ouattara K, Lemasson A, Zuberbühler K (2009b) Campbell's monkeys use affixation to alter call meaning. PLoS ONE 4:e7808. https:// doi.org/10.1371/journal.pone.0007808

Penner J, Fruteau C, Range F, Rödel M-O (2008) Finding a needle in a haystack: new methods of locating and working with rhinoceros vipers (Bitis rhinoceros). Herpetol Rev 39:310-314

Price T, Arnold K, Zuberbühler K, Semple S (2009) Pyow but not hack calls of the male putty-nosed monkey (Cercopithcus nictitans) convey information about caller identity. Behaviour 146:871888. https://doi.org/10.1163/156853908X396610

Price T, Fischer J (2014) Meaning attribution in the West African green monkey: influence of call type and context. Anim Cogn 17:277286. https://doi.org/10.1007/s10071-013-0660-9

Price T, Wadewitz P, Cheney D, Seyfarth R, Hammerschmidt K, Fischer J (2015) Vervets revisited: a quantitative analysis of alarm call structure and context specificity. Sci Rep 5:13220. https:// doi.org/10.1038/srep13220

R Core Team (2020) R: A language and environment for statistical computing, version 1.3.1093. R Foundation for Statistical Computing, Vienna, Austria, https://www.R-project.org/

Rainey HJ, Zuberbühler K, Slater PJB (2004) Hornbills can distinguish between primate alarm calls. Proc R Soc Lond B 271:755-759. https://doi.org/10.1098/rspb.2003.2619

Ramakrishnan U, Coss RG (2000) Recognition of heterospecific alarm vocalization by Bonnet Macaques (Macaca radiata). J Comp Psychol 114:3-12. https://doi.org/10.1037/0735-7036.114.1.3

Range F, Fischer J (2004) Vocal repertoire of Sooty mangabeys (Cercocebus torquatus atys) in the Tai National Park. Ethology 110:301-321. https://doi.org/10.1111/j.1439-0310.2004.00973.x

Rauber R (2020) Call order within vocal sequences of meerkats contains temporary contextual and individual information. BMC Biol 18:119

Rowe N (1996) The pictorial guide to the living primates. Pogonias Press, East Hampton

Schel AM, Candiotti A, Zuberbühler K (2010) Predator-deterring alarm call sequences in Guereza colobus monkeys are meaningful to conspecifics. Anim Behav 80:799-808. https://doi.org/10.1016/j. anbehav.2010.07.012 
Schlenker P, Chemla E, Arnold K, Zuberbühler K (2016) Pyow-hack revisited: two analyses of Putty-nosed monkey alarm calls. Lingua 171:1-23. https://doi.org/10.1016/j.lingua.2015.10.002

Seyfarth RM, Cheney DL, Marler P (1980) Vervet monkey alarm calls: semantic communication in a free-ranging primate. Anim Behav 28:1070-1094. https://doi.org/10.1016/S0003-3472(80)80097-2

Shalter M (1978) Localization of passerine seeet and mobbing calls by goshawks and pygmy owls. Z Tierpsychol 46:260-267. https:// doi.org/10.1111/j.1439-0310.1978.tb01448.x

Sherman PW (1977) Nepotism and the evolution of alarm calls. Science 197:1246-1253. https://doi.org/10.1126/science.197.4310. 1246

Shriner WM (1998) Yellow-bellied marmot and golden-mantled ground squirrel responses to heterospecific alarm calls. Anim Behav 55:529-536. https://doi.org/10.1006/anbe.1997.0623

Shultz S (2008) Population density, breeding chronology and diet of Crowned Eagles Stephanoaetus coronatus in Taï National Park, Ivory Coast. Ibis 144:135-138. https://doi.org/10.1046/j.00191019.2001.00005.x

Slater P, Rainey H, Zuberbühler K (2004) The responses of blackcasqued hornbills to predator vocalisations and primate alarm calls. Behaviour 141:1263-1277. https://doi.org/10.1163/15685 39042729658

Slobodchikoff CN, Paseka A, Verdolin JL (2009) Prairie dog alarm calls encode labels about predator colors. Anim Cogn 12:435439. https://doi.org/10.1007/s10071-008-0203-y

Stensland E, Angerbjörn A, Berggren P (2003) Mixed species groups in mammals. Mammal Rev 33:205-223

Stephan C, Zuberbühler K (2016) Persistent females and compliant males coordinate alarm calling in Diana monkeys. Curr Biol 26:2907-2912. https://doi.org/10.1016/j.cub.2016.08.033

Struhsaker TT (1967) Auditory communication among vervet monkeys (Cercopithecus aetthiops). In: Altmann SA (ed) Social communication among primates. University of Chicago Press, Chicago, pp 281-324

Struhsaker TT (1981) Polyspecific associations among tropical rainforest primates. Z Tierpsychol 57:268-304. https://doi.org/10. 1111/j.1439-0310.1981.tb01928.x

Suzuki TN (2012) Referential mobbing calls elicit different predatorsearching behaviours in Japanese great tits. Anim Behav 84:5357. https://doi.org/10.1016/j.anbehav.2012.03.030

Suzuki TN (2014) Communication about predator type by a bird using discrete, graded and combinatorial variation in alarm calls. Anim Behav 87:59-65

Suzuki TN (2016) Referential calls coordinate multi-species mobbing in a forest bird community. J Ethol 34:79-84. https://doi.org/10. 1007/s10164-015-0449-1

Templeton CN (2005) Allometry of alarm calls: black-capped chickadees encode information about predator size. Science 308:19341937. https://doi.org/10.1126/science.1108841

Townsend SW, Rasmussen M, Clutton-Brock T, Manser MB (2012) Flexible alarm calling in meerkats: the role of the social environment and predation urgency. Behav Ecol 23:1360-1364. https:// doi.org/10.1093/beheco/ars129
Venables WN, Ripley BD (2002) Modern Applied Statistics with S, 4th edn. Springer, New York

Vitousek MN, Adelman JS, Gregory NC, Clair JJHS (2007) Heterospecific alarm call recognition in a non-vocal reptile. Biol Lett 3:632-634. https://doi.org/10.1098/rsbl.2007.0443

Vooren AP (1986) Nature and origin of tree and branch fall in the Tai Forest (Ivory Coast). Neth J Agric Sci 34:112-116. https://doi. org/10.18174/njas.v34i1.16823

Walton B, Kershenbaum A (2019) Heterospecific recognition of referential alarm calls in two species of lemur. Bioacoustics 28:592603. https://doi.org/10.1080/09524622.2018.1509375

Wheeler BC (2010) Production and perception of situationally variable alarm calls in wild tufted capuchin monkeys (Cebus apella nigritus). Behav Ecol Sociobiol 64:989-1000. https://doi.org/10. 1007/s00265-010-0914-3

Wich SA, de Vries H (2006) Male monkeys remember which group members have given alarm calls. Proc R Soc Lond B 273:735740. https://doi.org/10.1098/rspb.2005.3320

Windfelder TL (2001) Interspecific communication in mixed-species groups of tamarins: evidence from playback experiments. Anim Behav 61:1193-1201. https://doi.org/10.1006/anbe.2000.1701

Wolters S, Zuberbühler K (2003) Mixed-species associations of Diana and Campbell's monkeys: the costs and benefits of a forest phenomenon. Behaviour 140:371-385. https://doi.org/10.1163/ 156853903321826684

Zuberbühler K (2000) Interspecies semantic communication in two forest primates. Proc R Soc Lond B 267:713-718. https://doi. org/10.1098/rspb.2000.1061

Zuberbühler K (2001) Predator-specific alarm calls in Campbell's monkeys, Cercopithecus campbelli. Behav Ecol Sociobiol 50:414422. https://doi.org/10.1007/s002650100383

Zuberbühler K (2002) A syntactic rule in forest monkey communication. Anim Behav 63:293-299. https://doi.org/10.1006/anbe. 2001.1914

Zuberbühler K (2004) Effects of natural and sexual selection on the evolution of guenon loud calls. In: Glenn ME, Cords M (eds) The Guenons: Diversity and Adaptation in African Monkeys. Kluwer Academic Publishers, Boston, pp 289-306

Zuberbühler K, Jenny D (2002) Leopard predation and primate evolution. J Hum Evol 43:873-886. https://doi.org/10.1006/jhev.2002. 0605

Zuberbühler K, Jenny D, Bshary R (1999) The predator deterrence function of primate alarm calls. Ethology 105:477-490. https:// doi.org/10.1046/j.1439-0310.1999.00396.x

Zuberbühler K, Noë R, Seyfarth RM (1997) Diana monkey long-distance calls: messages for conspecifics and predators. Anim Behav 53:589-604. https://doi.org/10.1006/anbe.1996.0334

Publisher's note Springer Nature remains neutral with regard to jurisdictional claims in published maps and institutional affiliations. 